\title{
Is a Possible-Worlds Semantics of Modality Possible? A Problem for Kratzer's Semantics
}

\author{
Zsófia Zvolenszky \\ New York University
}

\section{Introduction}

(1) Britney Spears must drink Pepsi.

(2) Britney Spears may eat spinach.

Modal sentences like (1) and (2) concern what is necessary or possible and delineating their truth conditions in terms of possible worlds therefore seems intuitive. Modal logicians--among others, Kripke (1963)--have done this, suggesting that (1) is equivalent to saying that it is necessary that Britney drink Pepsi, the truth of which requires that in every accessible possible world, Britney drink Pepsi, while (2) is equivalent to saying that it is possible that Britney eat spinach, merely requiring that in some accessible possible world, Britney eat spinach.

English auxiliary verbs signifying necessity include 'must', 'ought to', 'have to' and 'should'; those signifying possibility include 'may', 'might', 'can', 'is able to'. Accessibility is relative to some base world with respect to which a given sentence's truth value is determined (usually the actual world). The interpretation of modal sentences is relative in a further way: depending on the kind of modality invoked, the accessible worlds should do the following:

- make true what is known (epistemic reading),

- make true some relevant facts of the base world (circumstantial reading),

- fulfill what is required (deontic reading), or

- fulfill what is desired (bouletic reading), or

- $\quad$ obey conditions on a "nomal" course of events (stereotypical reading), etc.

Thus a deontic reading of (1) with respect to the actual world has it that given what is required by a certain law(s) or contract (Britney's advertisement contract with Pepsi, say), Britney must drink Pepsi, i.e., will drink Pepsi in every possible world in which the actual law or contract is fulfilled (these are the deontically possible worlds with respect to the actual world). The kind of modality invoked depends in part on the choice of lexical item (e.g. 'might' allows an epistemic reading but not a deontic one), and in part on the context of utterance (which can decide even among several, say, deontic readings--what is required by U.S. law, by Britney's contract, or by Britney's health).

This standard approach to modality has deficiencies that Kratzer (1977, 1981, 1991) aimed to correct while retaining much of the possible worlds framework posited by the standard analysis. But in the process, she left untouched a stubborn problem. In what follows, I will first explicate the problem (Section 2) and then identify its source and scope (Section 3). After examining two current attempts to solve the problem (Section 4), I will argue that a genuine solution calls for a 
revised conception of how possible worlds are to be specified, and how modal sentences are to be analyzed in terms of that specification (Section 5). Such a solution amounts to a radical revision and calls into question the very usefulness of a possible-worlds framework in analyzing modality.

\section{The Problem}

The problem, in a nutshell, is this: on Kratzer's $(1981,1991)$ analysis, all sentences of the form 'If $\mathrm{p}$ then it must be that $\mathrm{p}$ ' come out true, and so do most sentences of the form 'If $\mathrm{p}$ then it may be that $\mathrm{p}$ ' and this is so regardless of which kind of modality is invoked. What makes it a problem is that outlandish sentences like those under (3) come out true. I will refer to this as 'The Problem' throughout the paper.

a. If teenagers drink then teenagers must drink. (deontic reading invoking, say, U.S. laws) 'If teenagers drink then U.S. laws require them to do so.'

b. If teenagers drink then teenagers may drink. (deontic reading invoking, say, U.S. laws) 'If 18-olds drink then U.S. laws allow them to drink.'

c. If I file my taxes, then I must file my taxes. (bouletic reading invoking my desires) 'If I file my taxes then I want to file my taxes.'

d. If children don't eat spinach then children shouldn't eat spinach. (deontic reading invoking, say, considerations of health) 'If children don't eat spinach, then eating spinach is bad for them.'

In the light of a variation on Kratzer's analysis (like the double modalization strategy in Section 4.1), The Problem affects only non-epistemic modalities. I will therefore confine the examples to deontic and bouletic modalities. In general, on Kratzer's proposal, whatever one does, it is something one wants to do, and it is something that the law allows and even requires one to do. But it is evident that what one in fact does need not always be what one desires, or what is in accordance with the law or considerations of health.

It is no coincidence that all the sentences in (3) are conditionals. Indeed, The Problem arises because an independently motivated semantics Kratzer gives for conditionals ends up interfering with the semantics she posits for modal sentences. (I suspect that such an interference affects the chief alternative to Kratzer's account of conditionals--the classical logic account--but I do not have room to discuss this here. See Note 4.) In what follows, I will argue that keeping the semantics for conditionals requires that the simple facts in terms of which we specify possible worlds--e.g. who is drinking what in them--include what we might call modal or normative facts, the facts concerning what is a law, a desire, etc. ${ }^{1}$ Crucially, if I am right, then normative facts, (which I take to include modal facts) about a world turn out to be unanalyzable in terms of mundane facts of that world or other possible 
worlds. I will say that a possible-worlds framework is conventional just in case it specifies possible worlds exclusively in terms of nonmodal goings-on of that world and certain others. Both the standard analysis and Kratzer's are conventional frameworks. For example, according to the former, mundane facts of accessible worlds determine the normative facts of the base world. The upshot of this paper will be that there are no conventional revisions to solve The Problem. This could be taken to mean one of two things: that we cannot have an account that produces some conventional representation for each modal sentence; or that a conventional framework cannot fulfill all requirements on a unified account of modality. This paper is about the latter, more substantive kind of account.

Having discovered The Problem, I leamed that I was not the first to do so: Annette Frank (1997) describes it in her dissertation and proposes her own solution (discussed in Section 4.2). While Frank's is the most promising conventional solution, it ultimately fails. And the reason why it fails illuminates why The Problem does not admit of a conventional solution.

\section{The Source of The Problem}

Kratzer $(1981,1991)$ revises the standard modal analysis in two major ways: First, she distinguishes two dimensions of modal contribution--the modal base and the ordering source. Second, she calls for a revised interpretation of conditionals to replace the classical logic interpretation according to which a conditional's truth requires that either its first half (antecedent) be false, or that its second half (consequent) be true (see e.g. Grice 1967). Let me review these revisions in turn.

Recall that the standard modal analysis posits a range of possible worlds accessible from a given base world (call it $\mathrm{w}$ ). The accessible worlds make up a subset of all the logically possible worlds--those that provide consistent assignments of truth-values to the basic (atomic) statements such as 'Britney Spears drinks Pepsi', 'I file my taxes'. . We can think of the accessible worlds as making up the modal base $\mathrm{W}$ with respect to $\mathrm{w}$. The ordering source then imposes a partial ordering on the modal base W: some worlds in $\mathrm{W}$ are closer or more similar to w than others; some are equally close or similar to $\mathrm{w}$. The ordering is partial because there are pairs of worlds in $\mathrm{W}$ which are not ordered with respect to their closeness to w. Kratzer proposes the following revised truth conditions for modal sentences: ${ }^{3}$

(4) Kratzer's basic definition for modal sentences

For any sentence $p$, world $\mathrm{w}$, modal base $\mathrm{M}$, and ordering source $\mathrm{O}$ :

a. 'It must be that $\mathrm{p}$ ' is true in $\mathrm{w}$ relative to $\mathrm{M}$ and $\mathrm{O}$ iff $p$ is true in all the worlds closest (by O) to w within $\mathrm{M}$.

b. 'It can be that $\mathrm{p}$ ' is true in $\mathrm{w}$ relative to $\mathrm{M}$ and $\mathrm{O}$ iff $p$ is true in at least one of the worlds closest (by O) to w within M.

The modal base might be epistemically restricted (what is known in w is true in all worlds in w's modal base) or circumstantially restricted (some relevant truths 
of $\mathrm{w}$ are true across worlds in w's modal base). At the same time, the ordering source might be deontic (the more of w's laws are obeyed in a world, the closer it is to $w$ ), bouletic (the more of the desires in $w$ are fulfilled in a world, the closer it is to w), or stereotypical (the more a world follows a normal course of events, the closer it is to $\mathrm{w}$ ).

Consider, for example, a deontic reading of (2), invoking Britney's advertising contract with Pepsi (this is an utterance of (2) to the effect that the contract requires that Britney eat spinach). There is, say, no modal base restriction-the modal base comprises all logically possible worlds. The ordering source is deontic--among the worlds in the actual world's modal base, those in which all of the actual contract is obeyed are the closest. Because the contract does not bar Britney from eating spinach, in some of those closest worlds she does eat spinach, so (2) is true based on (4b).

Kratzer (1991) and others (e.g. Lewis 1975 and Heim 1982) have recommended a non-classical treatment of conditionals according to which their antecedents serve as restrictions on quantification, in the spirit of generalized quantifier theory. Consider the following core example:

(5) All porches have screens.

porch restricts the universal quantification to porches only, every single one of which must have screens in order for (5) to be true. On the same model, we can have antecedents of conditionals serve as restrictions on quantification over something like events/occasions; adverbs of quantification such as 'always', 'usually' provide evidence for this (see Lewis 1975); in the absence of such an adverb, there's default universal quantification. This way, (6)'s truth conditions are identical to (7)'s, which is a welcome result; both are true when among the horse-buying events/occasions performed by a man, all of them involve cash-paying by the man for the horse:

(6) If a man buys a horse, he pays cash for it.

(7) Always, if a man buys a horse, he pays cash for it.

Modal conditionals (like those in 3) can receive analogous treatment--but this time, quantification is over possible worlds. The antecedent serves to restrict the modal base, yielding the following truth conditions for modal conditionals:

(8) Kratzer's treatment of modal conditionals (to be combined with definition 4) For anysentences $p$ and $q$, world $\mathrm{w}$, ordering source $\mathrm{O}$, and modal bases $\mathrm{M}$ and $\mathrm{M}^{\mathrm{P}}$ :

a. 'If $p$ then it must be that $q$ ' is true in $w$ relative to $M$ and $O$ iff

'it must be that $\mathrm{q}^{\prime}$ is true in $\mathrm{w}$ relative to $\mathrm{M}^{\mathrm{p}}$ and $\mathrm{O}$, where $\mathrm{M}^{\mathrm{p}}$ contains all the worlds of $\mathrm{M}$ that make $p$ true.

b. 'If $p$ then it can be that $q$ ' is true in $w$ relative to $M$ and $O$ iff

'it can be that $q^{\prime}$ is true in $w$ relative to $M^{p}$ and $O$, where $\mathrm{M}^{\mathrm{p}}$ contains all the worlds of $\mathrm{M}$ that make $p$ true. 
To illustrate, let me work out the truth conditions of a deontic reading of (9) invoking Britney's advertising contract with Pepsi, assuming that the base world is the actual world and the initial modal base includes all logically possible worlds.

If Britney Spears drinks cola in public, then she must drink Pepsi.

By definition (8a), the antecedent clause restricts the initial modal base to those worlds in which Britney drinks cola in public (call this modal base $\mathrm{M}_{\text {COLA }}$ ). 'Britney must drink Pepsi' is then interpreted with respect to $\mathrm{M}_{\mathrm{COLA}}$ and a deontic ordering based on the terms of Britney's Pepsi contract. Because that contract does require that she not be seen dninking a cola other than Pepsi, possible worlds in which she drinks Pepsi in public fulfill more of the contract than worlds in which she drinks Coke in public. Hence, some Pepsi-drinking worlds are closer to the actual world than any Coke-drinking (or other cola brand) worlds. In all worlds in $\mathrm{M}_{\mathrm{COLA}}$, there's cola-drinking of some sort, so in all of the closest worlds that cola-drinking is Pepsidrinking. This is how, on definition (4a), 'Britney must drink Pepsi' is true.

Kratzer's framework is now in place for a straightforward demonstration of The Problem--how the framework cannot but make true the patently false sentences in (3). Recall that all of the sentences are either of the form 'If $p$ then it must be that $\mathrm{p}$ ' or 'If $\mathrm{p}$ then it may be that $\mathrm{p}$ '; the problematic outcome I am about to illustrate, carries over to just about any such sentence. The only exceptions are 'may' sentences for which the antecedent restricts the modal base to the empty set. I will demonstrate these results for (10) and (11).

(10) If Britney Spears drinks Coke in public, then she must drink Coke in public.

(11) If Britney Spears drinks Coke in public, then she may drink Coke in public.

As before, I assume that the actual world is the base world, that the initial modal base includes all logically possible worlds, and that the reading is a deontic one invoking Britney's Pepsi contract, requiring that she not drink non-Pepsi cola in public. Clearly, both (10) and (11) ought to come out false, given that the contract does not even allow, let alone require, that Britney drink Coke in public. But we get different results when we apply definitions (8) and (4). This time, the antecedent restricts the initial modal base to worlds in which Britney drinks Coke--call this modal base $\mathrm{M}_{\mathrm{COKE}}$; then all worlds that remain in $\mathrm{M}_{\mathrm{COKE}}$ violate the contract to some degree. Against $\mathbf{M}_{\mathrm{COKE}}$, we need to compute the truth conditions of 'Britney must drink Coke'. Among the worlds still in $\mathrm{M}_{\mathrm{COKE}}$, those deontically closest to the actual worlds will be worlds in which only the 'cola-drinking in public' clause of Britney's contract is violated, but the others are upheld. But those closest worlds of $\mathrm{M}_{\mathrm{COKE}}$ will still all be worlds in which Britney drinks Coke. Therefore, by definition (4a), 'Britney must drink Coke' is true relative to $\mathrm{M}_{\mathrm{COKE}}$ and the ordering based on Britney's actual contract, and hence (10) is true. Further, if there is at least one world left in $\mathrm{M}_{\mathrm{COKE}}$ (it seems trivial that there be a Coke-drinking world among the logically possible ones), then by definition (4b), 'Britney may drink Coke' is true and 
thus (11) is true.

As long as we have a non-empty modal base, the above pair of derivations goes through quite generally, for any sentences of the form 'If $p$ then it must be that p' and 'If $\mathrm{p}$ then it may be that p', regardless of the kind of modality invoked, rendering such sentences logical truths within Kratzer's framework; and such status is clearly unwarranted--the fact that I do something does not mean that I want to do it, or that I am allowed or required to do it.

Kratzer (1991) briefly noted an analogous problem conceming epistemic readings of modal sentences, but she did not seem to recognize the real scope or impact of The Problem. By contrast, Frank was fully aware of it and formulated it in the following general terms "any deontic conditional if $p$ then [it must be that] $q$ where $p$ implies $q$ will come out true, even if $q$ is not 'prescribed' by the deontic ordering source" (1997: 2.2.3). Indeed, (12) (below) is clearly false, for Britney's advertisement contract does not specify when she should be awake. But on Kratzer's analysis, (12) receives a treatment much like that of (10) and likewise comes out true:

(12) If Britney Spears dninks Pepsi at 4 a.m., then she must be awake at 4 a.m.. (deontic reading invoking Britney's advertisement contract with Pepsi) 'If Britney dninks Pepsi at 4 a.m., then her Pepsi-contract requires her to be awake at 4 a.m..'

The source of The Problem is easy to pinpoint: in Kratzer's framework, there are two truth-conditionally nonequivalent ways to achieve a modal base in which all of the closest worlds make true some sentence $p$ : either $p$ is the antecedent of a conditional, or 'it must be that $\mathrm{p}$ ' is true. In the framework, we cannot tell these two scenarios apart, and thus 'if $p$ then it must be that $p$ ' cannot but be true, because the antecedent and the consequent will, in effect, amount to the very same thing. Parallel reasoning carries over to the 'may'-sentences as well (as long as the restricted modal base is nonempty)--in 'if $\mathrm{p}$ then it may be that $\mathrm{p}$ ', the antecedent ends up implying the consequent. This is due to the conventionality of Kratzer's analysis--embodied in definition (4)--which specifies a link between the truth of a modal sentence and non-modal truths of other worlds (the closest ones). The source of the problem already suggests a direction for a solution: we need to make sure that the two distinct scenarios are in fact distinguishable in the framework. Representing the antecedents of conditionals as restricting the modal base is an independently plausible move (see e.g. Lewis 1975, Heim 1982, and Kratzer 1991) and revising it is unlikely to help with The Problem. ${ }^{4}$ This leaves us with the option of revising what it takes for 'it must be that $\mathrm{p}$ ' to be true.

We are about to examine, and ultimately reject, two conventional alternatives to Kratzer's analysis. Beforehand, let me give two reasons for why The Problem calls for a revised modal semantics, rather than a non-modal, or nonsemantic solution. First, sentences like (10) and (11) clearly have their false modal readings and a non-modal account of those would be ad hoc. Second, it is insufficient to posit a pragmatic constraint on deontic must to rule out (10) and (11) 
on the grounds that in them, facts (introduced by the antecedent) already settle the laws in question. Frank (1997: 4.1.3; see also 2.2.2) argues that such a constraint fails to generalize to all instances of The Problem (especially if we replace 'must' with 'is obliged to'). She concludes that "the observed tendency of deontic must, to be preferably uttered relative to a context where the fact denoted by its complement is not yet 'settled', has more to do with the pragmatic conditions associated with notions of demand vs. obligation rather than with the semantics of obligation proper (1997: 4.1.3)."

\section{Two Conventional Solutions}

In advocating an account of conditionals according to which antecedents serve as domain restrictions, Kratzer (1991) seems to aim for a unified account of conditionals--modal and nonmodal alike. A special treatment for modal conditionals (embodied in definition 8), gets in the way of this unification project. Many linguists (Schwarzchild, personal communication; see also Frank 1997: 2.2.2-3) have tried to capture Kratzer's goals by treating modal conditionals as doubly modalized: conditionals in general are implicitly modalized, while modal consequents introduce a second modal contribution. This amendment does indeed accomplish Kratzer's unification goal better than her own proposal. But does it dispose of The Problem? Section 4.1 explores this question, arriving at a negative answer.

Frank develops a dynamic semantic account of modality in the context of which she suggests a solution specifically targeting The Problem (1997: 4.1.3-4). In effect, she suggests that whenever we encounter a modal claim of the form 'it must be that p', the modal base with respect to which the claim is evaluated, should leave open whether or not $p$ is true. Thus if the original modal base made $p$ true, then it should be expanded to another modal base that leaves $p$ open. On this strategy, the problematic sentences of the form 'if $p$ then it must be that $p$ ' are no longer vacuously true. The second half of this section assesses this solution, finding that it comes at a hefty price: a closely related problem (which I will call the Flipside Problem) inevitably emerges. Further, the link between The Problem and the Flipside is indicative of what is fundamentally wrong with conventional solutions. Section 5 deals with the aftermath of this finding, and the outlines of a nonconventional alternative. My overall criticism of conventional solutions is largely independent of technical details of modal accounts; I have therefore tried to keep the discussion as nontechnical as possible.

\subsection{The Double Modalization Strategy}

In the spirit of Kratzer's (1991) unified semantics for conditionals, differences among material, counterfactual, deontic, epistemic, and other conditionals should be due to differences in the contextually contributed modal base and ordering source. The backbone of this idea is that conditional antecedents are always restricted quantifiers. This makes conditionals implicitly modalized: an antecedent provides 
further restriction on an initial modal base with respect to which an implicitly quantified consequent is evaluated. Conditionals behave as though they were equipped with an invisible modal operator in front of the 'if'-clause. For example, (13) is analyzed as implicitly quantifying over Britney's Vanilla Coke-sampling scenarios--in every such scenario, Britney keeps her Vanilla Coke consumption a secret.

If Britney Spears has tried Vanilla Coke, she has kept it a secret.

The initial modal base is plausibly epistemic (including worlds that are consistent with what the speaker, or what the public knows), and the ordering source stereotypical (the more a world follows a normal course of events, the closer it is to the base world). This way, (13) is equivalent to the explicitly quantified (14):

(14) If Britney has tried Vanilla Coke, she surely/necessarily has kept it a secret.

But (14) itself involves a modal operator, the epistemic 'necessarily', which we expect to be implicitly present in (13) as well.

These considerations call for the following definition:

(15) Kratzer's general treatment of conditionals

For any sentences $p$ and $q$, world $\mathrm{w}$, ordering source $\mathrm{O}$, and modal bases $\mathrm{M}$ and $\mathrm{M}^{\mathrm{P}}$ :

'If $\mathrm{p}$ then $\mathrm{q}$ ' is true in $\mathrm{w}$ relative to $\mathrm{M}$ and $\mathrm{O}$ iff

$q$ is true in all the worlds closest (by $\mathrm{O}$ ) to w within $\mathrm{M}^{\mathrm{P}}$, where $\mathrm{M}^{\mathrm{p}}$ contains all the worlds of $\mathrm{M}$ that make $p$ true.

a. For indicative conditionals, $\mathbf{M}$ is typically restricted to worlds that make true certain relevant facts (circumstantial) or what is known (epistemic), while $\mathrm{O}$ is stereotypical.

b. For counterfactual conditionals, $\mathrm{M}$ is empty and $\mathrm{O}$ is totally realistic (the more a world resembles w overall, the closer it is to w; this follows Lewis' (1973) proposal to order worlds based on overall similarity).

c. For the logician's material conditional, $\mathrm{O}$ is empty and $\mathrm{M}$ is totally realistic (restricted to worlds exactly like w).

Once we have a general account of modality on the one hand (definition 4), and conditionals on the other (definition 15), it seems reasonable to combine those to analyze modal conditionals like (9), repeated below:

(9) If Britney Spears drinks cola in public, then she must drink Pepsi.

Assuming an epistemic modal base $\mathrm{M}$ and a stereotypical ordering source $\mathrm{S}$ for the conditional, the antecedent further restricts $M$ to $\mathbf{M}_{\mathrm{COLA}}$, the cola-drinking worlds among $\mathrm{M}$ (by 15a); and we must further restrict our attention to the most normal of $\mathrm{M}_{\text {COLA }}$ worlds, $\mathrm{M}_{\text {COlanormal }}$ (because of $\mathrm{S}$ ). Next, we need to employ definition 
(4a) to check the truth of 'Britney must drink Pepsi' in each of the M Molanormal worlds. For Kratzer, this task would have involved checking if Britney drinks Pepsi in the MColanormal worlds (by 8a). By contrast, on the double modalization analysis, the task involves checking for each $\mathrm{M}_{\text {COLANORMAL }}$ world $\mathrm{v}$, whether in the deontically closest worlds among those within v's modal base N, Britney drinks Pepsi (by 4a). (Exactly what worlds does $\mathrm{N}$ include? I will tum to this crucial detail shortly.)

The above treatment has it that conditionals with modal consequents are doubly modalized: in addition to the overt modal in the consequent, the plain conditional itself comes with a covert (usually epistemic) modal. The modal operator of the consequent is then embedded in the scope of the modal operator of the entire conditional. This natural move renders definition (8)--designed especially for modal conditionals--superfluous.

Moreover, definition (8) is independently problematic. By itself, it is limited to capturing basic modal conditionals only; it becomes problematic, however, when combined with (15) to capture more complex conditionals like the counterfactual reading of (16):

If Britney Spears had ordered cola for lunch, she should have ordered Pepsi.

(Assume, as before, a deontic ordering based on the terms of Britney's Pepsi contract.) By (15b), Britney's cola-ordering worlds are ordered based on their overall similarity to the base world. But by (8a) and (4a), those same worlds must simultaneously be ordered based on how well they fulfill the terms of Britney's Pepsi contract. We thus have two potentially conflicting ordering sources. After all, Britney's actual cola-drinking habits need not (and probably do not) always agree with the terms of her Pepsi contract; so the most similar worlds need not be deontically the most ideal. Not only is it mysterious how these two conflicting ordering sources would be balanced against each other to yield a single world ordering; no such consolidated ordering would be plausible. For more extensive and illuminating discussion, see Frank (1997), Sections 2.2.2-3 and 4.1.4. ${ }^{5}$

By contrast, we can naturally combine definitions (15) and (4) to analyze (16) in much the same way as (9) has been analyzed a few paragraphs back: the already modalized conditional's similarity-based ordering is computed separately, prior to computing the embedded consequent's deontic ordering. The lesson then is that modal conditionals are not special conditionals; they just have special consequents (to be treated in accordance with definition 4). Every conditional itself is modalized (as reflected in 15), and conditionals with modal consequents are therefore doubly modalized. This double modalization alternative thus differs from Kratzer's two-dimensional treatment in replacing definition (8) by (15).

Next we should see how the double modalization altemative fares with respect to The Problem. To that end, we will first retum to the analysis of (9). Recall the last phase: checking for each M $\mathrm{M}_{\text {COLANORMAL }}$ world $\mathrm{v}$, whether Britney drinks Pepsi in the deontically closest worlds among those within v's modal base $\mathrm{N}$. The crucial question is whether there is a restriction on the modal base $\mathrm{N}$ for each $\mathrm{v}$. In 
particular, should some $\mathrm{N}$ for some $\mathrm{v}$ include worlds outside of $\mathrm{M}_{\text {COLA }}$ ? If it did, then $\mathrm{N}$ would include worlds in which Britney does not drink cola at all; some such worlds fulfill Britney's contract just as well as the deontically most ideal Pepsidrinking worlds do and are therefore among the deontically closest worlds to v. But then 'Britney must drink Pepsi' comes out false with respect to $\mathrm{v}$ (by 4a), making (9) false (by 15a). But (9) follows from Britney's Pepsi contract and hence should intuitively be true. To mend things, we have no choice but to make the modal base restriction from the antecedent carry over to the modal base of the consequent. That is, $\mathrm{N}$ is restricted to $\mathrm{M}_{\mathrm{COLA}}$, an outcome we can achieve by positing a circumstantial restriction on $\mathrm{N}$, based on the restriction due to the antecedent. ${ }^{6}$ Indeed, it is quite natural to expect a restriction like this to carry over to an embedded clause.

Now The Problem straightforwardly crops up, for (10) (repeated below) is still automatically true:

If Britney Spears drinks Coke in public, then she must drink Coke in public.

The antecedent restricts the initial modal base to $\mathrm{M}_{\mathrm{COKE}}$; we then need to evaluate the consequent with respect to each normal $\mathrm{M}_{\mathrm{COKE}}$ world. In each case, the Cokerestriction carries over to the modal base for 'Britney must drink Coke in public'. Thus deontically the closest worlds within the modal base are always worlds in which Britney drinks Coke. 'Britney must drink Coke' therefore comes out true (by 4a), making (10) true (by 15a). We are back to square one.

In sum, while the double modalization altemative constitutes an overall improvement on Kratzer's two-dimensional analysis, it offers no relief with respect to The Problem.

\subsection{Frank's Modal Base Expansion}

Kratzer's analysis, along with the double modalization improvement on it, can be translated into a dynamic semantic framework in which contextually and anaphorically supplied restrictions stand in for modal bases and ordering sources. In her dissertation, Frank works out the details of this and introduces a strategy--by appeal to a special kind of context reduction--that is custom-tailored to address The Problem (1997: 4.1.4). To keep the present discussion independent of a dynamic semantic framework, I will formulate an exact analog of context reduction--to be called Expansion--within Kratzer's framework and its variant, the double modalization alternative. I will then compare ways in which Frank puts Expansion to use (see also the Appendix). I aim to show that not only is Frank's application of Expansion to solving The Problem ad hoc; the apparent solution is also limited and ultimately unsuccessful. It amounts to plugging just one hole in an irreparably leaking boat; put a stopper in that one hole, and the water gushes in at another.

Intuitively, context reduction amounts to removing from the context of discourse a piece of information $p$ that had previously been considered given or part of the common ground. This way, $\mathrm{p}$ is left open, and both $\mathrm{p}$ and not-p scenarios come under consideration. The Kratzerian analog of context reduction can be 
described as modal base expansion: the process of removing a restriction $p$ from the specification of a modal base. Before the expansion, every world of the modal base (call it $\mathrm{M}^{\mathrm{p}}$ ) was a p-world; afterwards, the modal base may (though need not) have "doubled in size": it now includes any world that is exactly like some $\mathrm{M}^{\mathrm{p}}$ world as far as basic facts apart from $\mathrm{p}$ are concerned. That is to say, the resulting, expanded modal base is $\mathrm{M}$ itself. Whether the expanded modal base includes worlds other than these, depends on whether or not we want the modal base expansion to be minimal. Along with Frank (1997: 4.2.2), I am inclined to reject such a minimality constraint on expansion and will not employ it in the formulations here; but the problems I raise here do not hinge on rejecting this constraint. Modal base expansion--call it Expansion, for short--is thus exactly the reverse of the already familiar notion of restriction on a modal base.

Besides appealing to Expansion to address The Problem, Frank also recruits Expansion to resolve various kinds of inconsistencies in specifying modal bases. (Kratzer $(1981,1991)$ resolves these inconsistencies with the help of ordering sources.) In the Appendix, I describe these applications in some detail, discuss motivations behind them, and bring out crucial differences that set them apart from the application of Expansion to The Problem, defined below:

Frank's Expansion-based treatment of modal sentences

(to resolve The Problem through an amendment of definition 4)

For any sentence $p$, world $\mathrm{w}$, ordering source $\mathrm{O}$, and modal bases $\mathrm{M}$ and $\mathrm{M}^{\mathrm{p} / \mathrm{p}}$ 'it must be that $\mathrm{p}$ ' is true in $\mathrm{w}$ relative to $\mathrm{M}$ and $\mathrm{O}$ iff

'it must be that $\mathrm{p}^{\mathrm{\prime}}$ is true in all the worlds closest (by O) to w within $\mathrm{M}^{\mathrm{p} / \mathrm{p}}$, where $M^{p / p}$ is the result of Expanding $M$ with respect to both $p$ and its negation; this amounts to removing restrictions on $M$, if any, with respect to $p$ or $p$ 's negation; $\mathrm{M}^{\mathrm{p} / \mathrm{p}}$ thus leaves $p$ open.

Let me illustrate on (10) (repeated below) how (17) resolves The Problem:

(10) If Britney Spears drinks Coke in public then she must drink Coke in public.

The very fact that the consequent is about Britney's drinking Coke, erases any Cokedninking and non-Coke-drinking restrictions on the modal base. Thus the initial restriction due to the antecedent (in accordance with 15) is erased before we get to evaluating the consequent, and (10) is no longer true.

Beyond this success, what motivation is there for (17)? In effect, it amounts to saying that plain facts are never relevant to laws (or desires) for or against those facts; after all, (17) serves to dispose of the facts. Britney's drinking Coke is never relevant to whether she should or should not drink Coke. More generally, mundane facts (about what happens in a world) are never relevant to corresponding normative or modal facts--about what should or should not happen. This is not to say that mundane facts are not in any way relevant to normative facts, which may well be our verdict about 'even if conditionals. ${ }^{7}$ In the case of conditionals like (9) (repeated below), the very idea of a conditional law suggests that the antecedent (about a 
mundane fact such as Britney's drinking cola in public) is relevant to the consequent's taking effect (that Britney is required to drink Pepsi).

$$
\text { If Britney Spears drinks cola in public, then she must drink Pepsi. }
$$

This clause of Britney's advertisement contract does not require her to always drink Pepsi, just that she do so whenever the antecedent is fulfilled; otherwise, she is free to engage in a wide range of drinking and non-drinking activities that do not involve Pepsi, like drinking milk for breakfast or taking a nap.

In sum, mundane facts (as antecedents in conditional law constructions) are relevant to normative facts except those that correspond to or are implied (see 12 above) by the mundane fact in question. (17) is a rule formulated exclusively for capturing the desired exceptions. But are there reasons for positing exceptions beyond the need to circumvent The Problem? In the absence of further reasons to justify (17), it constitutes ad hoc patchwork, rather than a genuine solution to The Problem. And the reasons are not there. One might think otherwise, citing the very observation underlying The Problem: just because something happens need not mean that laws allow or require it; facts need not be sufficient for corresponding laws. But (17) captures a different claim--that facts can never be sufficient for corresponding laws/desires. Not only is this claim unsupported; there does not seem to be anything wrong with the idea of facts determining corresponding laws. We are about to see this based on (18) and (19):

(18) If Britney Spears pockets the cue ball, then she must pocket the cue ball. (deontic reading envoking the laws of nature)

(19) If Otto is racing down the tumpike then he shouldn't be racing down the tumpike. (deontic reading envoking traffic laws)

An advocate of determinism might voice (18), claiming that it does follow from any event or action that the laws of nature require it. The point is not that determinism holds, only that it is coherent position, and according to it, facts are sufficient for corresponding laws. Similarly, talking about someone who never obeys highway speed limits (call him Otto), we might say (19). In Otto's case, it does follow from his driving down the tumpike, that traffic laws prohibit driving at his speed, whatever that speed might be. That is to say, given certain background facts linking events and corresponding laws--facts about determinism, or Otto's speeding habits--mundane facts do allow for conclusions about corresponding normative facts. Admittedly, such background facts are not common; but this could well be because of issues unrelated to semantics (see the end of Section 3). Further, such background claims are definitely coherent, possible and sometimes even natural. An analysis of modality should therefore accommodate them. Even if determinism is false, semantic analysis is not the place to rule it out. Nor is it the place to rule out the existence of a perpetually speeding driver.

A straightforward way to accommodate these two possibilities would be to make the Expansion step in (17) optional, so we could skip Expansion in the case of 
(18) and (19). But this is a problematic move. An optionality amendment would fail to secure an illuminating and systematic account of modality, leaving open when to apply Expansion and when not. As things now stand, we would have nothing except the following guideline: use Expansion when and only when it makes the truthconditions come out intuitively right. Without independent characterization of the conditions for applying Expansion, this is no more substantive than the following rule for computing truth-values: for any sentence, flip the truth-value 'true' to 'false' whenever the sentence is intuitively false, and leave it as 'true' when the sentence is intuitively true.

By excluding the possibilities of determinism and a perpetually speeding driver, (17) nuns into a counterpart of The Problem, to which I am about to turm. Originally, The Problem exposed the following commitment of Kratzer's analysis: sentences of the form 'if $p$ then it must be that $p$ ' invariably come out true. Frank responds by positing (17), according to which such sentences--as well as those of the form 'if not-p then it must be that p' are no longer true. Frank's move is too radical in two ways. First, for Frank's (1997: 4.1-3) analysis without ordering sources, sentences of the form 'if not-p then it must be that p' are false even if a law requiring $p$ is in effect. For example, in a context in which concerns about safety require a speed limit, the true (20) turns out to be false on Frank's analysis.

(20) If there isn't a speed limit on this road, then there must be a speed limit on it. (deontic reading envoking considerations about safety)

The falsity of (20) is due to Frank's application of Expansion to resolving inconsistencies: antecedents that violate laws effectively dispose of those laws (for more details, see the Appendix). Consequently, sentences of the form 'if $p$ then it may be that p' are invariably true. For example, Frank's analysis has it that in the context of a law prohibiting murder, the intuitively false (21) comes out true:

(21) If there is murder then there may be murder.

'If there is murder then the laws allow murder.'

(20) and (21) are already devastating for any conventional analysis that--like Frank's--posits modal bases but not ordering sources. There is, however, a second, more general problem facing (17), for which ordering sources offer no help. Indeed, I will argue that this new problem--the Flipside Problem--does not admit of a solution any more than The Problem does: with a conventional solution, we are either stuck with The Problem, or with the Flipside, but we cannot resolve both. The Flipside Problem is this: sentences of the form 'if $\mathrm{p}$ then it must be that $\mathrm{p}$ ' are never true when the consequent is not already true. But beyond (18) about determinism there are plausibly true instances of such conditionals, some of which are listed in (22) below. 
(22) The Flipside Problem

(a) If The Dalai Lama is mad, then he should be mad. (deontic reading envoking considerations about reasonable reactions) 'If The Dalai Lama is mad, then (given his even temper) he must have his reasons.'

(b) If Yogi Bear works then he has to work/is obliged work. (bouletic reading envoking Yellowstone ranger John Smith's demands)

(c) If Bart Simpson listens to Bartók, then he must/is obliged to do so. (bouletic reading envoking, say, Marge's demands)

For (22a), assume as background that The Dalai Lama is extremely mildmannered, so he does not get mad unless he has very good reasons for doing so. The antecedent restricts the modal base to worlds in which The Dalai Lama is mad (by 15a). Expansion then removes this restriction (by 17), so the modal base against which we evaluate the consequent includes worlds in which he is not mad. Then 'The Dalai Lama should be mad' is false (by 17), making (22a) false (by 15a). Exactly parallel steps show how (22b) and (22c) also come out false.

Two further considerations make the Flipside Problem even more pointed. (17) prevents us from so much as representing background claims of the sort we have seen in (22). But (22a) would be a plausible way of rendering a claim about The Dalai Lama's character: that he does not get mad without having good reasons for it. This point could draw further support from the classical-logic correspondence between if-conditionals and only if-conditionals (see Dekker 2001 for recent arguments). Based on this, (22a-c) are equivalent to the even more natural (23a-c), which make entirely plausible background claims about The Dalai Lama, Yogi Bear, and Bart Simpson, respectively.

(23) (a) The Dalai Lama is mad only if he has to be mad.

(b) Yogi Bear works only of he has to.

(c) Bart Simpson listens to Bartók only if he has to.

So far, we have seen that the one conventional solution to The Problem that successfully resolves it--by appeal to Expansion--lacks independent motivation, and also generates further problem cases: the Flipside Problem. We have already seen that it is no coincidence that disposing of The Problem by means of Expansion leads to the Flipside Problem: The Problem had been due to an unwanted link between mundane facts and normative facts in Kratzer's analysis. Removing this link by means of Expansion amounts to never allowing a link between mundane facts and normative facts. The Flipside Problem shows that this is not right either. The remainder of the paper explicates further the relation between The Problem and the Flipside, aiming to establish that getting rid of both problems takes a nonconventional solution, which will be outlined at the end. 


\section{A Non-conventional Solution}

The hallmark of conventional frameworks--like Kratzer's, Frank's, and others--is that they specify possible worlds exclusively in terms of nonmodal goings-on in certain worlds. Whenever the framework is faced with representing a normative fact, that fact is to be read off from mundane facts of a selected set of possible worlds. For example, 'Britney must drink Pepsi' is represented by a certain set of worlds all of which involve Pepsi-drinking on Britney's part. The conditions for arniving at such sets of worlds are therefore critical--whether we are looking at normal worlds only, deontically the closest worlds, or an Expanded modal base, becomes crucial. After all, the goings-on of the worlds in the resulting modal base are supposed to be sufficient for normative facts that we read off from that modal base. This is why tinkering with modal bases in different ways has been occupying center stage within the present paper. The aim was to see if the rules for aniving at modal bases can be formulated so that for (10) (repeated below), by the time we get to evaluating 'Britney must drink Coke', the modal base includes worlds with no Coke-dninking by Britney. Otherwise, Coke-drinking across the modal base would have sufficed to make the normative fact 'Britney must drink Coke' true. And given the domain restriction view of conditionals, this would have made (10) true as well.

If Britney Spears drinks Coke, then she must drink Coke.

The Problem and the Flipside put demanding requirements on the modalbase tinkering: The Problem forces us to accommodate scenarios in which intuitively, certain mundane facts are not sufficient for normative facts. At the same time, the Flipside forces us to accommodate scenarios in which intuitively, mundane facts just like those featured in The Problem, are sufficient for normative facts just like those featured in The Problem. This pair of requirements puts impossible demands on a conventional framework: a representation of normative facts in terms of mundane facts cannot do justice to both problems, for it cannot distinguish Problem-type cases in which the mundane should not suffice for the normative, from Flipside-type cases in which the mundane should suffice for the normative. To put the issues differently, it is in the nature of mundane and normative facts that the latter are sometimes independent of the former in certain ways (as demonstrated by The Problem) and sometimes dependent on them (as demonstrated by the Flipside Problem). The representation of the mundane and the normative should therefore leave open the possibility of dependence, without requiring it. This is an impossible task for the representational apparatus of any conventional framework.

What is the altemative if we give up on conventional frameworks? Normative facts--laws, desires--are sui generis in a strong sense: they do not admit of analysis in terms of mundane facts; they hold in a possible world solely because they are normative facts of that possible world. Just as two worlds might differ from each other in their mundane goings-on, they can also differ from each other in their normative facts--laws, desires that hold in them. This way, (10) is false because in every world that shares (among others) the actual world's normative facts and in 
which Britney also drinks Coke, the following normative fact holds: given Britney's advertising contract, she must not drink Coke. Likewise, $(22 b)$ is true because in every world that shares (among others) the actual world's normative facts, and in which Yogi Bear works, the following normative fact holds: given John Smith's demands, Yogi Bear has to work.

This sketch of a non-conventional alternative might prompt the following worry, which disappears on closer inspection. Specifying normative facts of possible worlds is complicated because we need to specify so many of them (see Frank 1997: 2.2.3). For example, what might appear like a single normative fact--Britney's Pepsi contract requiring that she drink Pepsi in public whenever she drinks cola--has an infinity of instances, which are also normative facts of the actual world: Britney must drink Pepsi if she drinks cola in public on New Year's Eve 2002; if she drinks cola for breakfast; if she drinks cola in Memphis, and so on. This worry is unfounded: despite the multitude of instances, specifying them is no more a problem than specifying mundane facts of the actual world--a task facing conventional and non-conventional frameworks alike. From 'Every U.S. President was born on American soil', a long range of mundane facts follow: that Nixon was born on American soil, as was Carter, Reagan, and so on. It also follows that if Gore, McCain, or others become President then they too were born on American soil. In addition, if Quayle or Dole had become President then they would have been born on American soil. Predicate logic serves to generate all of these instances (see also Note 2). That logic (suitably expanded as desired) can generate multitudes of normative facts with just as much ease as it generates mundane facts.

Not only is the outline of a non-conventional solution that I have presented quite brief; it does not seem to leave much room for further development either. Most importantly, this non-conventional alternative specifies normative facts without even mentioning possible worlds. Normative facts hold in a world just as simply as mundane facts do. The omission of possible worlds in analyzing normative facts is therefore by no means accidental, but a distinctive feature of any non-conventional analysis. Conventional frameworks have carried the promise of analyzing normative facts of a world in terms of relations the world bears to other possible worlds. The Problem and the Flipside Problem cast doubt on the viability of such frameworks. But the very reason why possible worlds initially had seemed so useful in analyzing modality was that instead of taking normative facts of worlds to be simple, one hoped substantively to analyze them based on relations among possible worlds. Now that this option has been undermined, it is no longer clear what real work possible worlds could accomplish within an adequate account of modality.

Giving up on the possible-worlds analysis is bound to seem disappointing. But I am inclined to think that there is nothing disappointing about it; for the standard, possible-worlds analysis is not all that much more substantive or explanatory than a non-conventional account. For example, certain inferential relations--e.g. 'p is allowed' follows from 'p is required'--which the possible worlds analysis can easily secure, can still be secured through other, logic- or lexicon-based means. This area merits further exploration. Also, possible worlds help analyze a 
law in terms of its satisfiability: deontically closest worlds satisfying the law. But it is unclear how this is a deeper explanation of a normative fact than that provided by the non-conventional analysis, which simply appeals to which normative facts hold at the base world, and which do not. Satisfiability neither seems illuminating nor sufficient for an explanation of nomative facts. Indeed, what makes conventional analyses vulnerable to The Problem and the Flipside is that they equate normative facts with their satisfiability. Therefore, pursuing a satisfiability-based account of modality--i.e. a possible-worlds account of modality--could well rest on a mistake.

\section{Appendix}

Frank (1997) puts Expansion to use in two ways--resolving inconsistencies in modal base restrictions, and resolving The Problem. In what follows, I will describe the former in some detail, in order to bring out crucial differences between the two applications. Below are two ways in which inconsistent restrictions can arise:

- For counterfactual conditionals, the antecedent is inconsistent with actual facts which could be part of a circumstantial modal base. That is, we have a conflict between facts.

- Conditional laws may have antecedents that conflict with some basic law, as we see in the Samaritan Paradox involving a pair of laws such as: 'There must not be murder' and 'If there is murder, a jury should convene'. The conflict is brought out when we consider murder scenarios--which violate the first law. Intuitively, the second law is still in effect, requiring that a jury convene.

In each of these situations, the standard modal analysis (which appeals to modal bases but not ordering sources) would put inconsistent restrictions on the modal base, thus making it empty. But that leads to an unpalatable outcome: against an empty modal base, all 'must'-sentences are vacuously true (due to universal quantification over worlds), and all 'can'-sentences, vacuously false (due to existential quantification). This is clearly not what we want in the case of counterfactuals or the Samaritan Paradox.

To account for inconsistencies, $\operatorname{Kratzer}(1981,1991)$ appeals to the notion of an ordering source, which would order worlds within a modal base without requiring that the closest worlds maximally fit the specifications. This way, we are not faced with an empty modal base--if the closest worlds all violate the law prohibiting murder, or leave one of several desires unfulfilled, those are still the worlds we consider, since they come closer to the base world than others included in the modal base.

Because Frank wants to get by without ordering sources (see Note 5), she appeals to an alternative account, in terms of Expansion (1997: 4.2-3). First, she distinguishes two kinds of contributions to the modal base restriction: the factual and the non-factual. Roughly, the former is a counterpart of Kratzer's modal base restriction (epistemic or circumstantial), while the latter is a counterpart of Kratzer's ordering source (deontic or bouletic). When combined, the two kinds of contribution 
result in a complete modal base restriction to yield a modal base of worlds. Importantly, Expansion can now work in two ways to achieve consistent modal base restrictions: if there is conflict between previous factual restrictions and a factual antecedent, then Expansion reduces the previous factual restrictions; if there is conflict between previous non-factual (i.e. normative) restrictions and a factual antecedent, then Expansion reduces the previous non-factual restrictions.

For counterfactual conditionals (like 16 above) Expansion erases factual restrictions that are inconsistent with the counterfactual antecedent (Frank 1997: 4.3). There is nothing surprising or contrived about employing Expansion along these lines. After all, counterfactual conditionals are about invoking alternative states of affairs in which not all of reality holds. The very meaning of these conditionals licenses that we disregard certain facts.

In the case of the Samaritan Paradox, evaluating a conditional of the form 'if murder occurs then $\mathrm{p}^{\prime}$ prompts us to add the occurrence of murder to the facts already restricting the modal base. This creates a conflict with a non-factual modal base restriction--that murder is prohibited. Expansion allows us to omit this law and achieve a non-empty modal base (Frank 1997: 4.2.1). The conditional law requiring a jury in murder cases continues to restrict the modal base, so it includes only those murderous worlds in which juries convene. Again, there is nothing odd or artificial about this application of Expansion. Laws are not always obeyed; so it is reasonable to posit the "conflicting" pair of laws in the Samaritan Paradox, to cover scenarios in which the absolute law prohibiting murder is violated. When the violation does take place (or is hypothesized), the conditional law steps in to require a jury, while the absolute law is no longer a source of guidance. Hence, disregarding the latter in connection with murder-scenarios is a natural move. This approach generates a new problem for Frank which she does not address (See 20 and 21 above).

It is important to note that these two applications of Expansion can be viewed as instances of a unified treatment. The phenomena and the strategies for Expansion are related in the two cases. For not only does the Expansion-based solution encompass all applications, but an alternative solution in terms of ordering sources (as seen in Kratzer), also takes care of the examples in one fell swoop. Moreover, these applications of Expansion are quite natural. By contrast, Frank's (1997) application of Expansion to The Problem stands apart from these other applications: the phenomena are different; the Expansion strategy itself is different; and the rule to accomplish Expansion lacks motivation independently of The Problem. To see all this, let me examine Expansion in the context of the Problem more closely (see also Section 4.2).

For starters, The Problem does not involve a conflict between facts or laws; instead, we have patently false conditionals that amount to logical truths within Kratzer's theory. (A more general problem about unwanted consequences also arises: whenever the modal base includes $\mathrm{p}$, 'it must be that $\mathrm{p}$ ' is automatically a consequence.) It is not surprising then that Frank's strategy for dealing with The Problem is also different (1997: 4.1.3-4): The goal is not to remove a conflict that would lead to an empty modal base; instead, we need to Expand the modal base when evaluating a modal sentence of the form 'it must be that $q$ ' to make sure that 
the modal base does not establish $q$ or its negation. (See definition 17 above.)

Also, there is a crucial structural difference between how Expansion is intended to resolve inconsistencies, and how it is intended to resolve The Problem. In the former application, the modal base against which we evaluate the consequent depends in part on the antecedent, and in no part depends on the consequent. By contrast, in the latter application, the modal base against which we evaluate the consequent of a conditional is itself in part determined by that consequent. For example, when evaluating (10), the very fact that the consequent is about Britney's drinking Coke erases Coke-drinking and non-Coke-drinking restrictions on the modal base.

Definition (17) is also unusual in that it calls for a revision of factual restrictions. For other applications of Expansion, we have already noted that only counterfactual conditionals license factual revision. Other conditionals (in connection with the Samaritan Paradox) license non-factual revisions onlyallowing that laws or desires be suspended. In the absence of a counterfactual motivation, the factual revision that Frank calls for is without precedent.

\section{Endnotes}

* For discussion, I thank members of the NYU Fall 2001 Semantics Seminar and participants of SALT 2002. Special thanks go to Kit Fine for very helpful written comments, Roger Schwartzchild for discussion at the early stages, three anonymous SALT reviewers for crucial suggestions, and most of all, to Anna Szabolcsi, for many thoughtful comments and much encouragement.

1. This proposal about normative facts need not render it inconsistent with a nonfactualist position about modality (see Gibbard 1990).

2. On this conception of possible worlds--which constitutes a departure from Kratzer--all logical consequences of what is true in a world are already worked out and part of that world's specification. If, for example, it is true in a world that if $p$ then $q$ and also $p$, then $q$ is automatically true. This way, definitions that are equivalent to Kratzer's can be constructed in simpler ways, without recourse to the notions of consequence and compatibility.

3. To keep the definition uncluttered, I simplified it so it assumes that there is always a closest world. But Lewis (1973) pointed out that this does not always hold; his amendment can be straightforwardly incorporated in definition (4).

4. A basic implementation of the classical logic account of conditionals does not avoid The Problem: making (10) false would require the base world to make the antecedent true, and some accessible world to make the consequent is false. It is unclear how this could be accomplished within a conventional framework, due to considerations parallel to those at the end of Section 4.1.

5. Frank (1997: 2.2.3) argues that the distinction between ordering source and modal base is unnecessary. We can get by without ordering sources, by having deontic/bouletic/stereotypical restrictions on modal bases in just the way that epistemic and circumstantial restrictions apply to modal bases. My arguments in Section 4 carry over to Frank's formulation as well. I will nevertheless continue appealing to ordering sources--to keep the discussion straightforwardly related to the nowfamiliar Kratzerian framework. In the Appendix I discuss Frank's account without ordering sources.

6. Frank (1997: 2.2.3) comes up with a solution along these lines, proposing a different, anaphoric mechanism for carrying over the antecedent restriction to the consequent. She further shows that in addition to the antecedent restriction, the normalcy restriction (due to the conditional's ordering

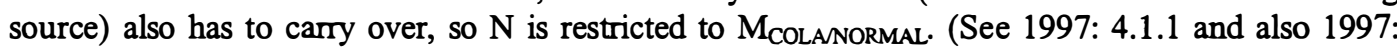
4.3.) While her point is not crucial to the present discussion, it is worth noting that she has thereby created a slew of new, problematic examples related to The Problem. For the following will automatically be true: 'If Britney drinks cola then things will proceed normally' and 'If Britney drinks cola then things must proceed normally'. More generally, any sentence of the form 'if $p$ then things 
will/must/may proceed normally' is guaranteed to be true.

7. The semantics of 'even if conditionals plausibly makes the antecedent irrelevant to the consequent in a deontic reading of 'Even if Britney drinks Coke, she must dnink Pepsi'. See Frank (1997: 2.2.2).

\section{References}

Dekker, P. 2001. 'On If and Only'. in R. Hastings, B. Jackson, and Zs. Zvolenszky (eds.), Proceedings of SALT XI, Cornell University, Ithaca, 114-133.

Frank, A. 1997. Context Dependence in Modal Constructions. Ph.D. Dissertation, Universität Stuttgart.

Gibbard, A. 1990. Wise Choices, Apt Feelings: A Theory of Normative Judgment. Oxford.

Grice, P. 1967. Logic and Conversation. Manuscript.

Heim, I. 1982. The Semantics of Definite and Indefinite Noun Phrases. Ph.D. Dissertation, University of Massachusetts at Amherst.

Kratzer, A. 1977: 'What "Must" and "Can" Must and Can Mean'. Linguistics and Philosophy 1, 337-355.

Kratzer, A. 1981. 'The Notional Category of Modality'. in H. J. Eikmeyer, and H. Rieser (eds.). Words, Worlds, and Contexts. Berlin, 38-74.

Kratzer, A. 1991. 'Modality'/'Conditionals'. in A. von Stechow, and D. Wunderlich (eds.). Semantik. Ein internationales Handbuch der zeitgenössichen Forschung. Berlin, 639-659.

Kripke, S. 1963. 'Semantical Considerations on Modal Logic'. Acta Philosophica Fennica 16, 83-94.

Lewis, D. K. 1973. Counterfactuals. Oxford.

Lewis, D. K. 1975. 'Adverbs of Quantification'. in E. L. Keenan (ed.) Formal Semantics of Natural Language. Cambridge, 3-15. 